\title{
Levantamento do Quadro Patológico do Complexo do Ginásio Poliesportivo Ismaelino Moreira Pontes no Município de Tucuruí/PA.
}

\author{
Jehnnye. da Silva Damasceno Santos ${ }^{1 *}$, Jeffson. Taveiro Cruz Santos ${ }^{2}$, Janiele. Moreira Roland ${ }^{3}$, \\ Jéssyca. Carolinne Santos Lacorte ${ }^{4}$, Dinilza. Melo Cohen Ribeiro ${ }^{5}$ \\ * jehnnyedamasceno@gmail.com* janieleroland@hotmail.com* jeffsontaveiro@gmail.com* \\ carolinnelacorte@gmail.com*dinilza20@hotmail.com* \\ ${ }^{1}$ Faculdade de Engenharia Civil, Universidade Federal do Pará, Tucuruí, Brasil \\ ${ }^{2}$ Faculdade de Engenharia Civil, Universidade Federal do Pará, Tucuruí, Brasil \\ ${ }^{3}$ Faculdade de Engenharia Civil, Universidade Federal do Pará, Tucuruí, Brasil \\ ${ }^{4}$ Faculdade de Engenharia Civil, Universidade Federal do Pará, Tucuruí, Brasil \\ ${ }^{5}$ Faculdade de Engenharia Civil, Universidade Federal do Pará, Tucuruí, Brasil
}

\section{RESUMO}

As patologias presentes em muitas edificações, normalmente, são resultado de muitos equívocos que são cometidos nas fases de projeto, execução ou uso das edificações, ou até mesmo pela falta de manutenção preventiva. Em função do crescimento acelerado das cidades com novas construções, sem o planejamento devido e execução correta, assim como a falta de manutenção em edificações antigas, tornou-se comum o desenvolvimento de trabalhos e estudos de detecção e análise das diversas manifestações patológicas observadas em prédios públicos e privados das nossas cidades. Neste trabalho é apresentado um levantamento das manifestações patológicas observadas e suas prováveis causas no ginásio poliesportivo Ismaelino Moreira Pontes, localizado no município de Tucuruí/PA. Foi realizado um levantamento superficial de diversos tipos de patologias, estruturais ou não, existentes na estrutura e componentes pertencentes ao complexo, apresentando algumas sugestões, como procedimento de manutenção e reparos, estabelecendo assim critérios para se aplicar medidas preventivas e de fiscalização das causas prováveis das patologias. Vale ressaltar que o conhecimento das causas que originam as patologias nos edifícios e a utilização de medidas preventivas, quer seja na fase de projeto, seja nos cuidados minuciosos na fase de execução e posterior manutenção, resultam em uma economia considerável se comparado ao custo com medidas de recuperação, que muitas vezes não são bem executadas, sendo assim ferramentas fundamentais para minimizar o surgimento dessas patologias.

Palavras chave: Patologia, Manifestações Patológicas, Ginásio; Projeto; Manutenção.

\begin{abstract}
The pathologies present in many buildings, are usually the result of committed mistakes in the design phase, execution or its use, or even the lack of preventive maintenance. In function of the
\end{abstract}


accelerated growth of cities with new construction unplanning due and correct execution, as well as lack maintenance in old buildings, has become common the development of works and studies of detection, as well as review of several pathological manifestations observed in public and private buildings of our cities. This work presents a survey of pathological manifestations and its probable causes in the multi-sport gym "Ismaelino Moreira Pontes", in Tucuruí/PA. A superficial survey of several kinds of pathologies was conducted, structural or not, existing in the structure and elements belonging to the complex, presenting some suggestions as maintenance procedures and repairs, establishing criteria to apply preventive measures and supervision of the probable causes of the pathologies. It is noteworthy that the knowledge of the causes that give rise to pathologies in buildings and the use of preventive measures, either in the design phase, the minute care in the execution phase, or subsequent maintenance, result in considerable savings compared to the cost recovery measures, which are often not well executed, therefore, essential tools to minimize the appearance of these pathologies.

Key Words: Pathology: Pathological Manifestations: Gym: Project; Maintenence.

\begin{abstract}
O
Las patologías presentes en muchos edificios generalmente ser el resultado de muchos errores que se cometen en las fases de diseño, ejecución o uso de los edificios, o incluso debido a la falta de mantenimiento preventivo. Debido al crecimiento acelerado de las ciudades con nueva construcción, sin una adecuada planificación y ejecución correcta, así como a la falta de mantenimiento en las edificaciones antiguas, se hizo común desarrollar trabajos y estudios para la detección y análisis de las diversas manifestaciones patológicas observadas en las edificaciones públicos y privados en nuestras ciudades. Este trabajo presenta un relevamiento de las manifestaciones patológicas observadas y sus probables causas en el gimnasio polideportivo Ismaelino Moreira Pontes, ubicado en el municipio de Tucuruí / PA. Se realizó un relevamiento superficial de varios tipos de patologías, estructurales o no, existentes en la estructura y componentes pertenecientes al complejo, presentando algunas sugerencias, como procedimiento de mantenimiento y reparación, estableciendo así criterios para aplicar medidas preventivas e inspección de las probables causas de las patologías. Cabe mencionar que el conocimiento de las causas que provocan patologías en los edificios y el uso de medidas preventivas, ya sea en la fase de diseño, o en el cuidado detallado en la fase de ejecución y posterior mantenimiento, redundan en ahorros considerables en comparación con el costo con medidas de recuperación, que muchas veces no están bien ejecutadas, siendo así herramientas fundamentales para minimizar la aparición de estas patologías.
\end{abstract}

Palabra Clabe: Patología, Manifestaciones Patológicas, Gimnasio; Proyecto; Mantenimiento.

\title{
1. INTRODUÇÃO
}

O estudo das patologias em edificações começou a ganhar importância à medida que foi se intensificando problemas no comportamento da estrutura. Pode-se dizer que a vida útil de um material tem sua durabilidade diretamente ligada a sua conservação e manutenção, uma vez que 
está submetido a ações direta ou indiretamente do meio em que está exposto. Segundo Helene (2003 apud SILVA, 2008) as ocorrências envolvendo patologias nas edificações possuem características de manifestações externas e internas, e a partir dessas ocorrências, deve-se diagnosticar a natureza, a origem e os mecanismos dessas patologias.

A princípio o interesse por esses estudos foram voltados para manifestações provocadas em estruturas de concreto armado e foram se expandindo para as ocorrências em revestimentos com argamassas, revestimentos cerâmicos, pinturas, estruturas metálicas e assim por diante. De acordo com Costa Jr. (2001 apud SILVA, 2008), a origem das patologias não está concentrada em fatores isolados, isso se dá pelo fato de sofrerem a influência de um conjunto de variáveis atuantes, que podem ser classificadas de acordo com fatores como: o processo patológico, os sintomas, a causa geradora dos problemas ou ainda com a etapa do processo produtivo em que ocorrem.

Para Souza e Ripper (1998), no que se refere ao surgimento da patologia na estrutura de concreto, há inúmeras limitações que devem ser superadas no que diz respeito ao desenvolvimento científico e tecnológico da engenharia civil, as quais associadas a falhas involuntárias, deterioração, ausência de perícia, irresponsabilidades e acidentes, resultam em condições propícias ao desempenho insatisfatório da estrutura.

A ocorrência de vários diagnósticos envolvendo patologias estruturais está relacionada muitas vezes, à ineficiência quanto à manutenção das estruturas, ou seja, existe quase que um abandono total das edificações de modo que o nível de deterioração muitas das vezes chega a não somente comprometer a estética em uma estrutura e sim ao comportamento e a funcionalidade em que está sujeita, de modo que se ocorresse à manutenção preventiva e pequenos reparos, os custos seriam menores, evitando gastos desnecessários.

Para garantir uma maior vida útil às edificações proporcionando desempenhos satisfatórios, tanto no que diz respeito a sua estrutura quanto a sua funcionalidade, é indispensável à realização de uma manutenção adequada, e diante disso, fazer parte de um processo mais amplo de gestão, que identifique, através de vistorias periódicas, os danos existentes, diagnosticando-os e indicando as ações de recuperação, afirma Vitório (2005 apud ALVES, 2012).

A importância de se fazer um levantamento sobre as patologias existentes em um local determinado está relacionada ao diagnóstico de possíveis danos que venham futuramente comprometer a resistência e a trabalhabilidade de uma estrutura. Mediante isso, é necessário obter informações suficientes para o conhecimento da evolução das patologias e dessa forma fornecer soluções voltadas à prevenção e reparação dos danos presentes.

\section{MÉTODOS}

Para realizar o levantamento das patologias existentes no complexo esportivo, realizou-se várias visitas no local. Essas vistorias foram necessárias para obter informações sobre o registro do período da sua construção, tempo da edificação, tipos de manutenção realizada, material utilizado, os projetos da edificação, entre outros. Todas essas informações foram buscadas na administração do complexo e na secretária de obras do município, porém, poucas informações nos foram repassadas, visto que nem a planta baixa foi encontrada.

$\mathrm{O}$ acesso na área do complexo esportivo foi limitado por questões administrativas. Durante o processo de vistoria não foi permitido, por parte da administração local, escavações, perfurações e retirada de materiais para análise quantitativa das patologias. Os registros fotográficos também foram limitados, seguindo a orientação administrativa, o que dificultou a realização de uma vistoria mais ampla. Para verificar quais as anomalias existentes no local, foram utilizados alguns materiais, na maior parte para métodos de análise não-destrutiva, tais como: fissurômetro, solução de fenolftaleína, trena, e em poucos casos, a talhadeira e martelo. O teste de carbonatação 
e classificação de aberturas e fissuras, foram realizadas dentro das limitações estabelecidas. Em função de todos estes intervenientes citados, esse trabalho está sendo apresentado com base em uma análise qualitativa, uma vez que o acesso a informações e autorização para realizar uma avaliação quantitativa foi limitado, não sendo possível ter maiores detalhes sobre às causas das anomalias detectadas e a situação real da estrutura em estudo. As figuras 2.1 e 2.2 mostram os materiais utilizados no método de análise.
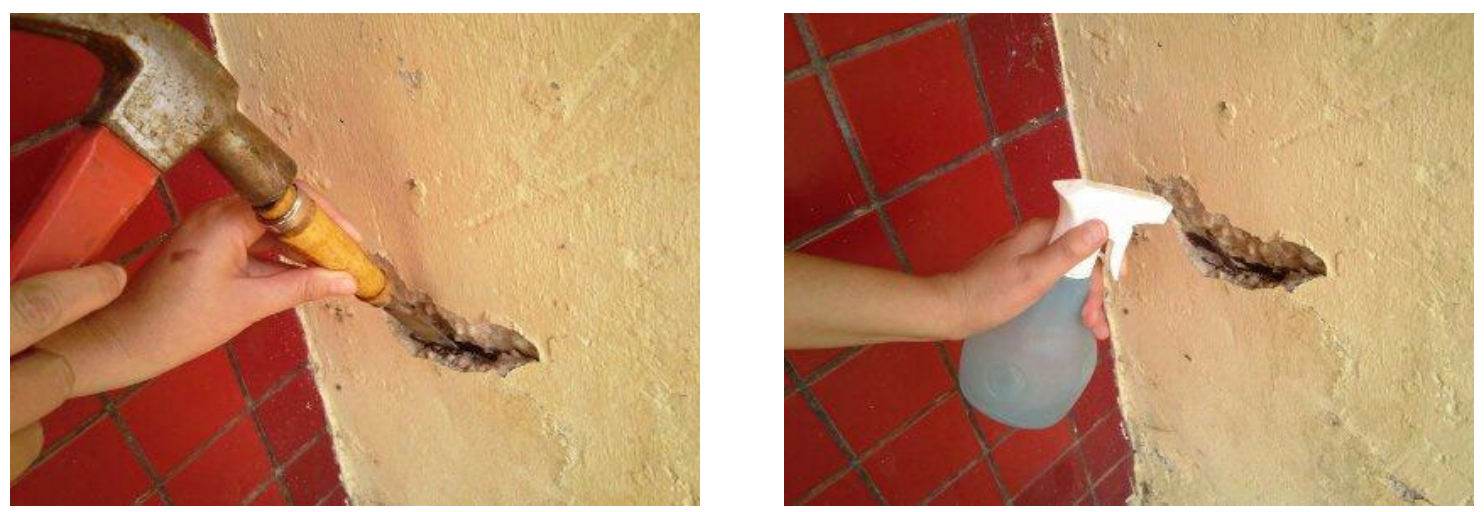

Figura 2.1. Materiais utilizados no método de análise.

\section{RESULTADOS}

\subsection{Eflorescência}

A ocorrência da eflorescência nas superfícies das peças de concreto podem alterar a aparência das mesmas, sobre a qual se depositam e em determinados casos seus sais constituintes podem ser agressivos, causando a deterioração da estrutura. A figura 3.1 mostra os trechos dos pilares P1, P2, P4, P5, P6, P7, P8, P9, P10, P11, P12, P13, P14, P15 e P18 onde há a presença dessa patologia.
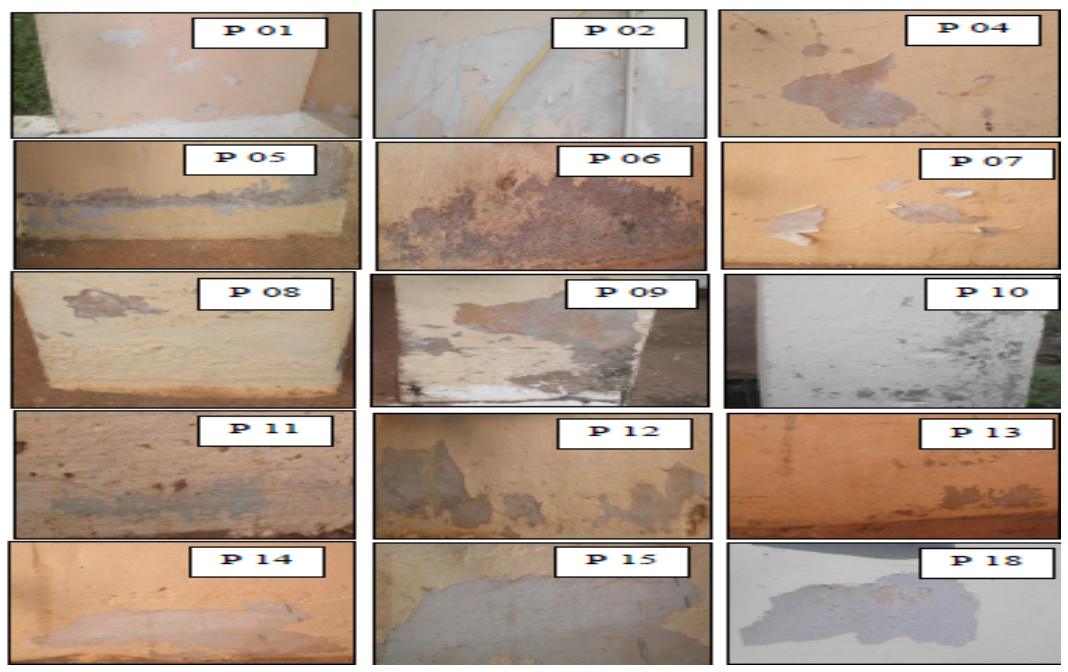

Figura 3.1. Trechos com eflorescência nos pilares.

Observa-se que em todos os pilares apresentados na figura 3.1, encontram-se manchas esbranquiçadas presentes em sua superfície, sendo esta, uma das características da eflorescência. Para uma melhor visualização quantitativa, o gráfico 3.1 apresenta a porcentagem dos pilares externos que apresentam essa patologia.

Eflorescência

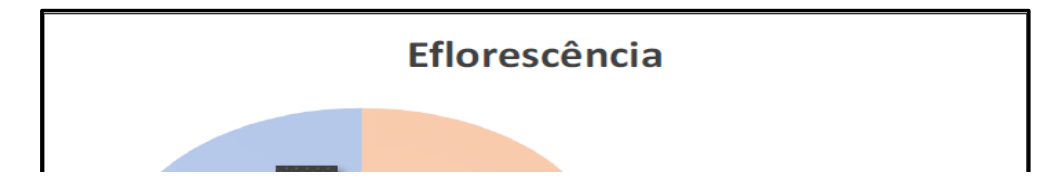

XVI Congreso Latinoamericano de Patología de la Construcción 


\section{.Gráfico 3.1- Quantitativo de pilares com eflorescência.}

Como observa-se no gráfico, mais da metade dos pilares apresentaram indícios de eflorescência. Essa patologia, como já foi dito anteriormente é causada devido a presença de sais que podem ter várias origens, dentre elas: as matérias-primas, os materiais de construção, a água existente no subsolo, entre outros; e que são dissolvidos quando entram em contato com a umidade decorrente da infiltração pelo subsolo ou mesmo de água pluviais. Uma das consequências mais comuns da eflorescência é o descolamento da pintura e o aparecimento de manchas brancas sobre a superfície do concreto, que pode gerar um aspecto aparente desagradável. Entretanto, esse tipo de patologia deve ser tratado com uma maior atenção, uma vez que a eflorescência pode causar a desagregação do concreto resultando na ruína da estrutura. Nesse caso, como medida de prevenção, deve-se buscar conhecer a origem e os mecanismos da eflorescência, a natureza dos sais e principalmente eliminar ou reduzir a possibilidade de umidade utilizando cimentos do tipo: CP IV (com adição de pozolana), tipo RS (resistente a sulfato), ou o cimento CP III (com baixo teor de hidróxido de cálcio e uma eficiente cura do concreto), tendo uma baixa porosidade superficial, com uma argamassa mais densa, impermeável e menor porosidade capilar.

\subsection{Bolor e Limo}

Outra patologia identificada na quadra poliesportiva foi a presença de bolor e limo. Durante a avaliação, observou-se nos pilares que em muitos trechos há a presença de bolor e limo, como mostra a figura 3.2 Percebeu-se que a fachada e a marquise também apresentavam uma quantidade considerável de bolor como mostra a figura 3.3.

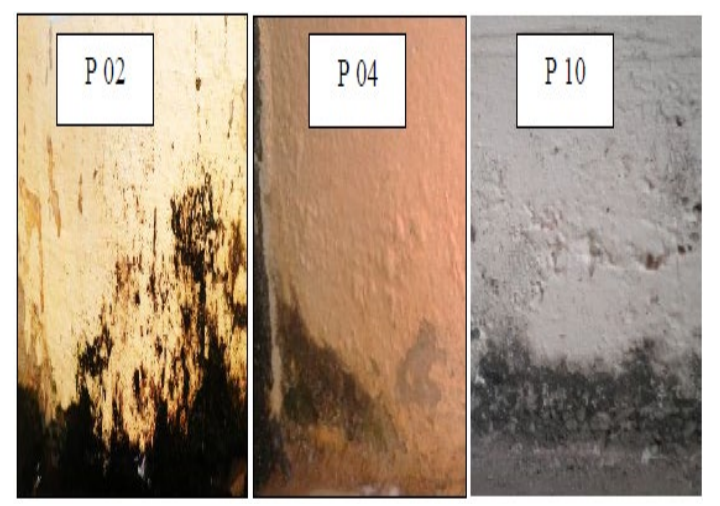

Figura 3.2. Base dos pilares com bolor e limo. 

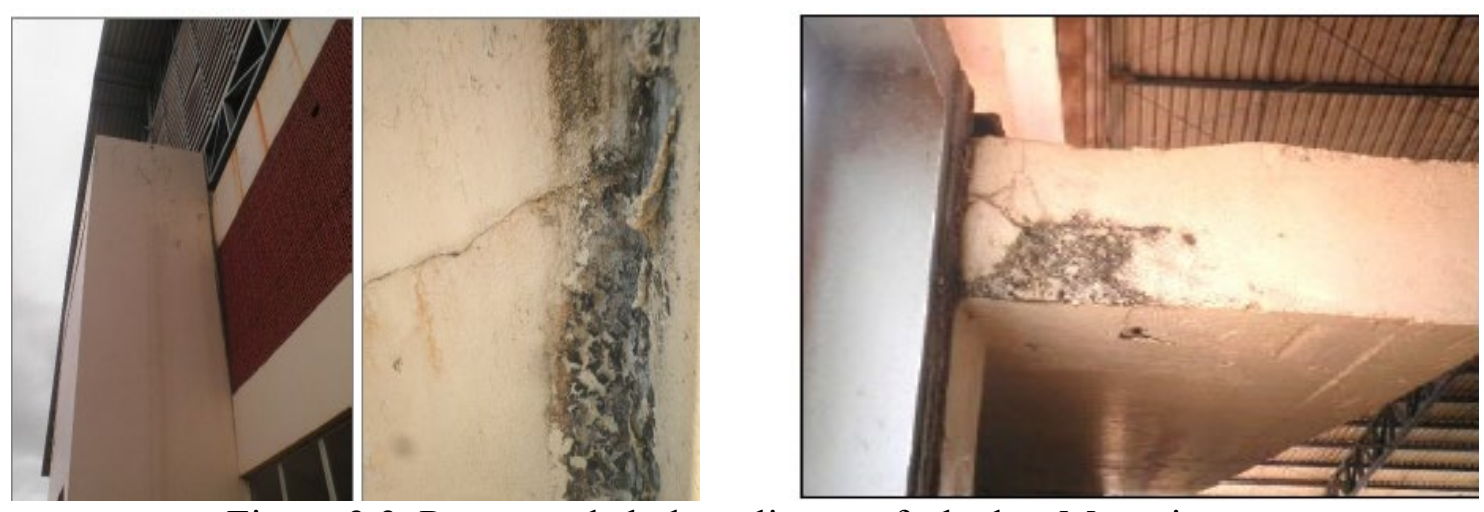

Figura 3.3. Presença de bolor e limo na fachada e Marquise.

Uma das causas prováveis para o surgimento dessas patologias seria a presença de umidade na estrutura de concreto, onde sua superfície sofre uma alteração, determinando em muitos casos, que seja feito uma recuperação ou até mesmo a aplicação de uma nova camada de revestimento. Alucci, Flauzino e Milano (1985 apud SOUZA, 2008), reforçam a ideia de que medidas de prevenção são indispensáveis para se evitar que o bolor aconteça nas edificações. Uma dessas medidas seria na fase de elaboração do projeto, onde deve ser garantida uma ventilação, iluminação e insolação adequada aos ambientes, bem como idealizar a diminuição de risco de condensação nas superfícies internas dos componentes, além de buscar evitar riscos de infiltração de água através de paredes, pisos e/ou tetos.

Todavia caso o projeto não tenha previsto esses fatores, e consequentemente a patologia ocorra, e caso não seja possível a prevenção, deve ser realizada a limpeza da superfície removendo a patologia, com emprego de soluções fungicidas podendo até ocorrer a troca de materiais que estejam contaminados por outros que resistam a ação de crescimento do bolor (SOUZA, 2008). No caso do ginásio, os pontos onde verificou-se a existência de bolor e limo, são locais ventilados, com iluminação natural frequente, visto que a maioria desses pontos estão nas colunas externas da quadra. Sendo assim observa-se que uma das possíveis causas para o surgimento dessas patologias seja o contato com a água proveniente da chuva, em função de respingos ou pela infiltração sofrida pelo solo e também da limpeza dos banheiros e dos vestiários.

Outro ponto encontrado com bolor foi a marquise. Para essa situação, o surgimento deve estar relacionado a falta de iluminação, ventilação e insolação, uma vez que a marquise está localizada dentro da quadra, que é um ambiente fechado, abafado, com pouquíssima ventilação. Também foi observado que a mesma fica em uma área totalmente desprotegida da água da chuva. Imagina-se que possivelmente não foram utilizados produtos impermeabilizantes durante a construção da mesma. Ou ainda, no caso de ter sido utilizado impermeabilizantes, a falta de manutenção contribui para a propagação e surgimento do bolor e do limo na estrutura.

\subsection{Carbonatação}

Para verificação da patologia de carbonatação, foram realizados testes com o emprego de fenolftaleína para a comprovação da possível existência.

O teste consiste na aplicação da solução na superfície recém exposta do concreto. A solução de fenolftaleína foi aplicada nos pontos onde havia desplacamento do concreto nos pilares externos da quadra do ginásio conforme figura 3.4, e em alguns pontos da caixa d'água nas figuras 3.5. 

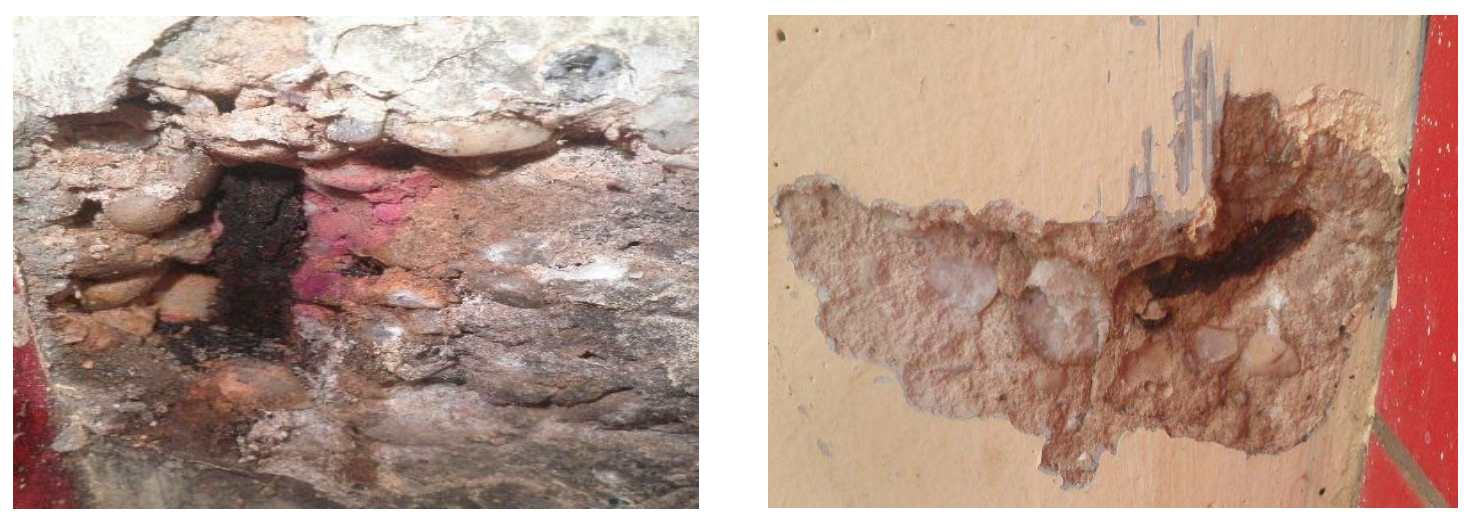

Figura 3.4. Trechos com carbonatação na quadra do ginásio.
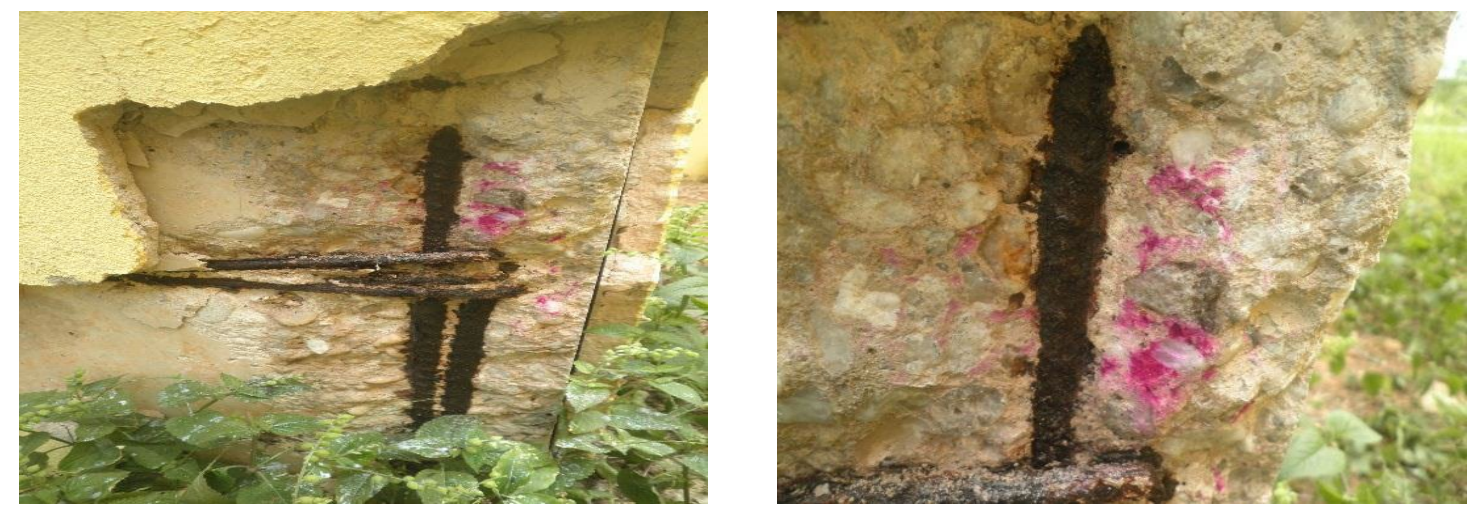

Figura 3.5. Trechos com carbonatação na caixa d'água.

Observa-se nas figuras 3.4e 3.5 que nos elementos estudados foi notado a presença de CO2. Este processo ocorre a uma velocidade decrescente, pois o $\mathrm{CO} 2$ tem que se difundir através do sistema de poros, incluindo a região já carbonatada da superfície do concreto. A carbonatação provoca a redução do $\mathrm{pH}$ do concreto propiciando a despassivação da armadura. Com isso ocorre o processo de corrosão da armadura e posteriormente a expansão do aço, resultando no desplacamento do concreto. Isso causa a exposição da armadura deixando-a mais suscetível a agentes agressivos, havendo a perda da seção da armadura e consequentemente uma diminuição na resistência da peça. Outra consequência da carbonatação é a alteração da permeabilidade e do volume de poros do concreto em razão das alterações microestruturais causadas pelas reações químicas citadas na revisão bibliográfica, afirma Castro (2003).

Para combater a carbonatação, tem-se como método de prevenção medidas básicas, tais como: a armadura do concreto tem que ter o cobrimento mínimo necessário conforme as especificações estabelecida na NBR 6118:2014, que trata sobre Projeto de estrutura de concreto - procedimento; dosar o concreto com aditivos plastificantes ou superplastificantes; utilizar uma baixa relação a/c, proporcionando assim uma menor porosidade e sempre que possível, usar revestimento sobre a superfície de concreto armado.

\subsection{Fissuras}

Percebeu-se que nos pilares de concreto armado da quadra poliesportiva há presença de fissuras em muitos pontos. A figura 3.6 mostra o P1 e o P10 com várias fissuras no sentido longitudinal do elemento. 


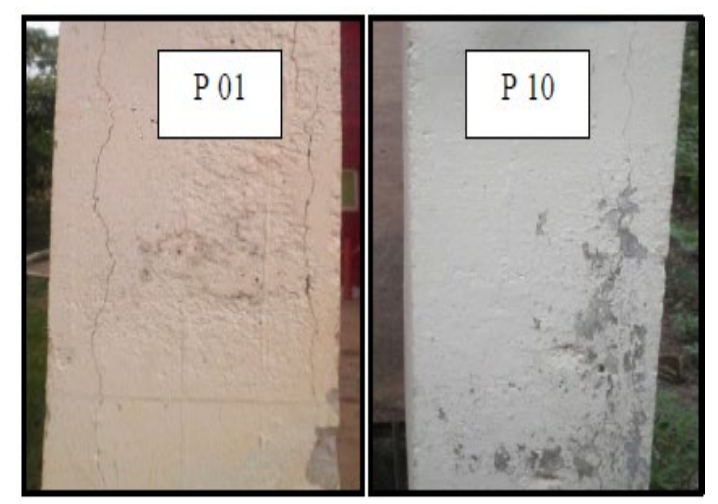

Figura 3.6. Pilar com fissuras.

Observa-se na figura 3.6 que os pilares apresentam fissuras ao longo da sua seção e em alguns trechos já indicam risco de desplacamento do concreto. Alguns pilares estão com a presença de aberturas e em alguns pontos apresentam-se com parte do concreto desplacado. A figura 3.7 indica esses pilares.

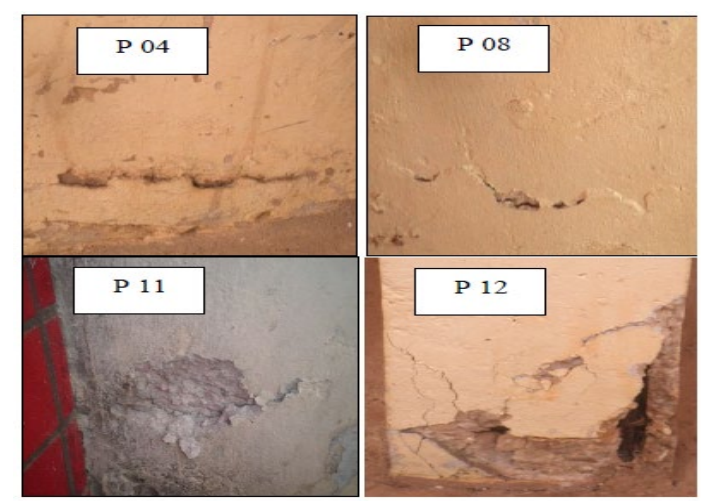

Figura 3.7. Pilares com aberturas e desplacamento do concreto.

Também foram notadas a existência de fissuras nas paredes e nos pilares do palco da quadra poliesportiva e em uma parede da sala de aula de balé. A figura 3.8 expõem a localização das fissuras observadas no palco e a 3.9 a indica a localização da fissura na sala de balé.

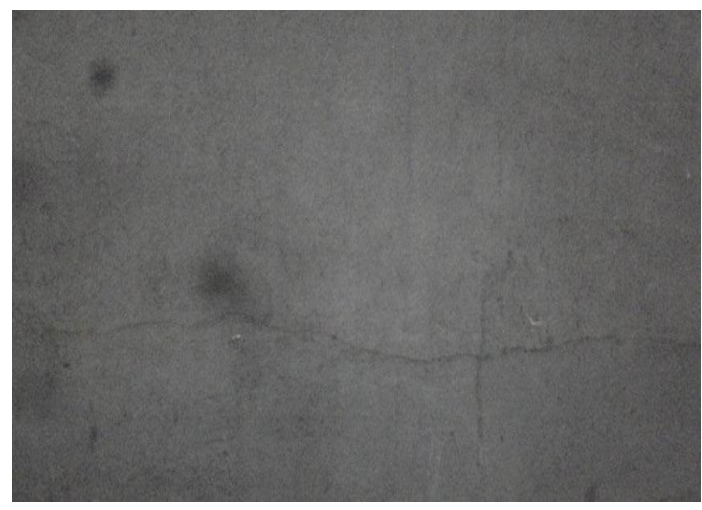

Figura 3.8. Fissuras no sentido transversal nas paredes e pilares do palco. 


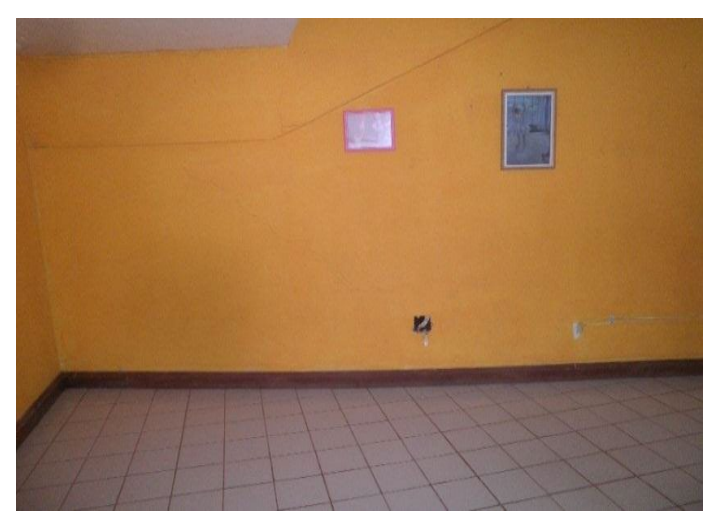

Figura 3.9. Fissuras na parede da sala de balé.

Faz parte do complexo tem-se uma caixa d'água que serve de apoio para o abastecimento do local. Na base da mesma notou-se fissuras na camada de revestimento, como mostra a figura 3.10 e 3.11 .
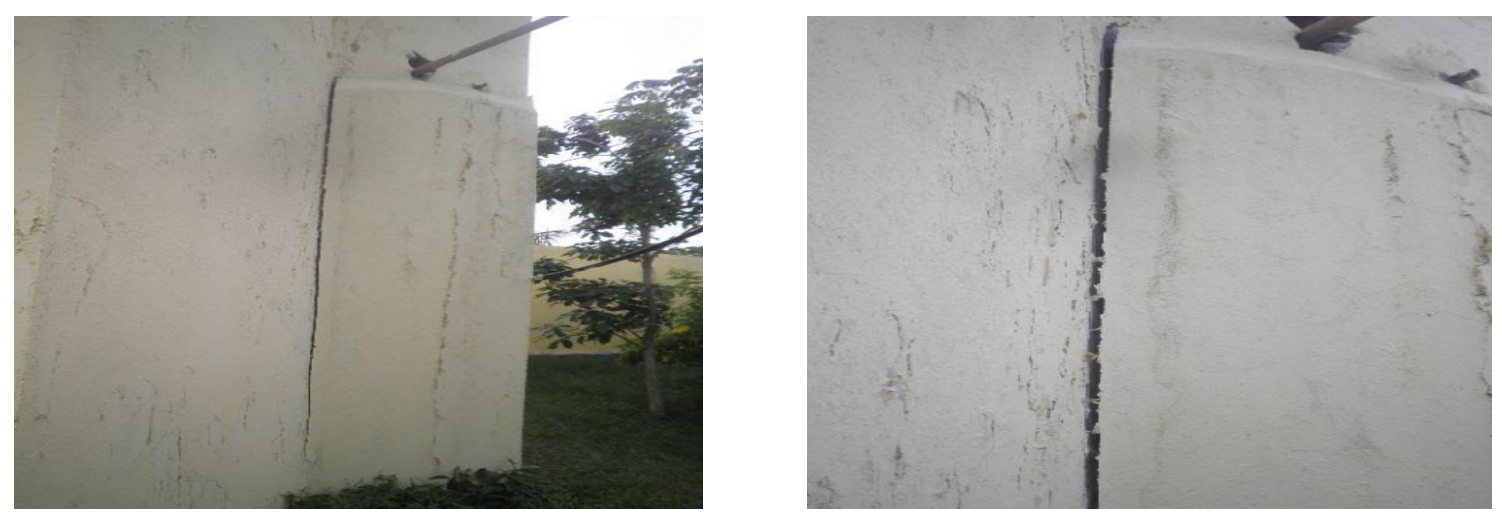

Figura 3.10. Descolamento do revestimento da caixa d'água.
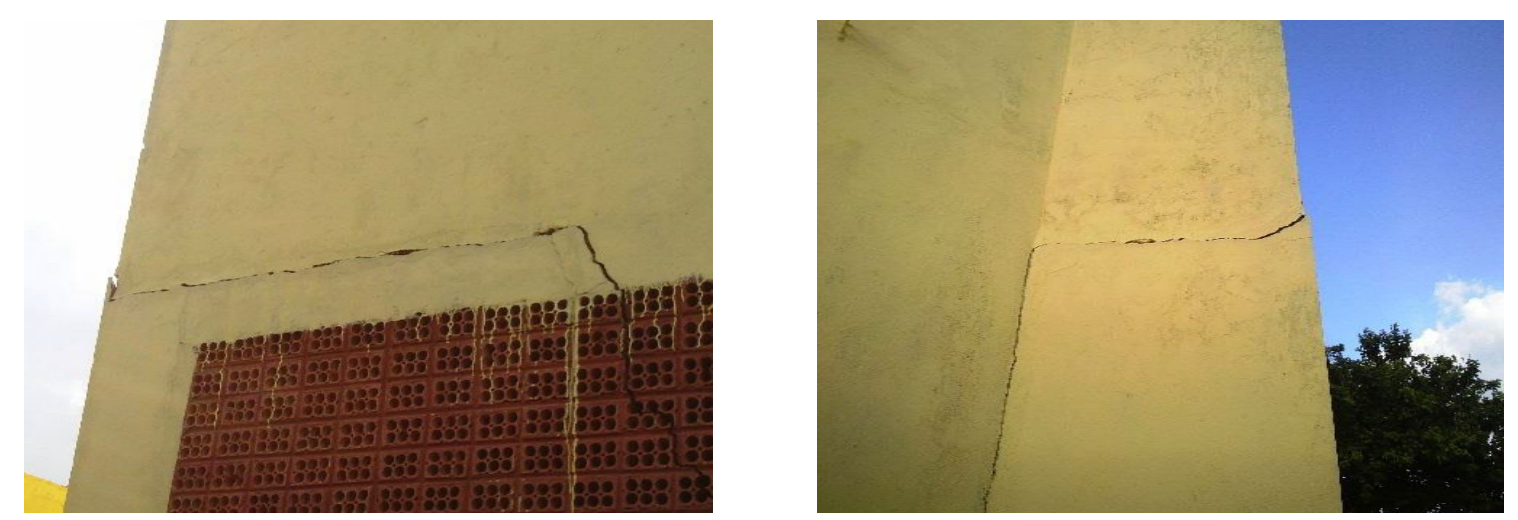

Figura 3.11. Caixa d'água com fissuras excessivas.

Percebeu-se que o reboco aplicado sobre a estrutura da caixa d'água apresenta fissuras e aberturas, inclusive com o risco de desplacamento do mesmo sobre os usuários do local. Tal fato pode ser atribuído a falta de aderência entre a superfície do concreto com o revestimento, provavelmente pela ausência do apicoamento recomendado para facilitar a aderência do reboco a superfície do concreto. Utilizando o medidor de fissuras, realizou-se em alguns pontos a verificação do tipo de abertura apresentada na caixa d'água conforme figura 3.12, e nos pilares da quadra poliesportiva figura 3.13. 

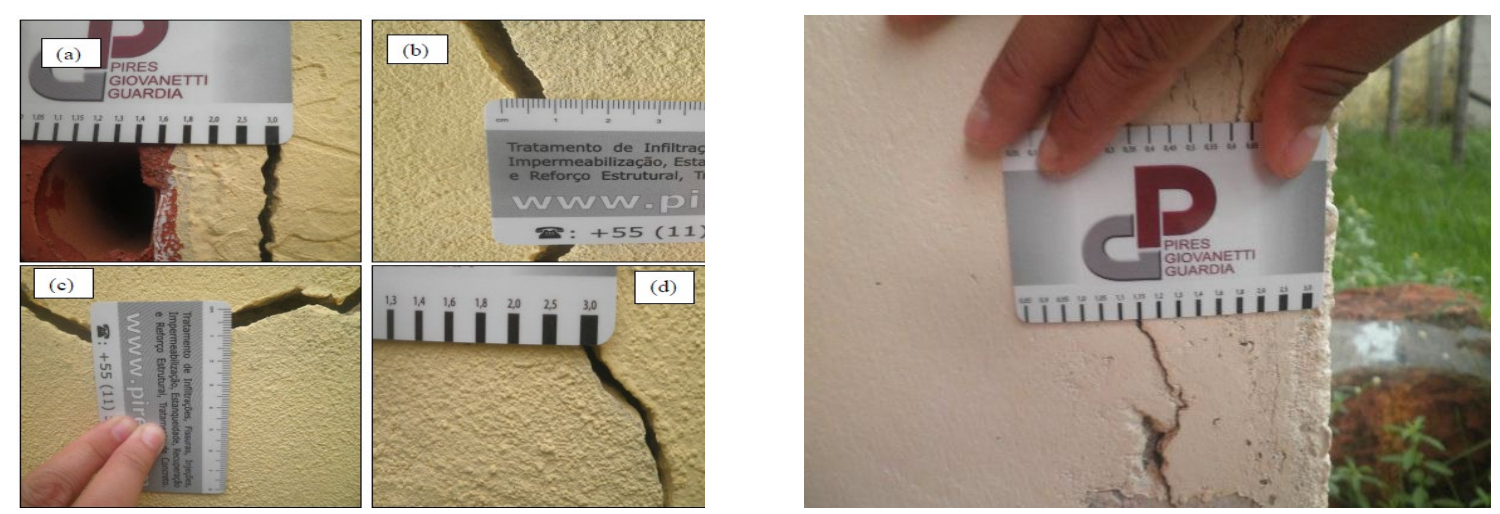

Figura 3.12. Verificação de aberturas na caixa d'água utilizando o fissurômetro.
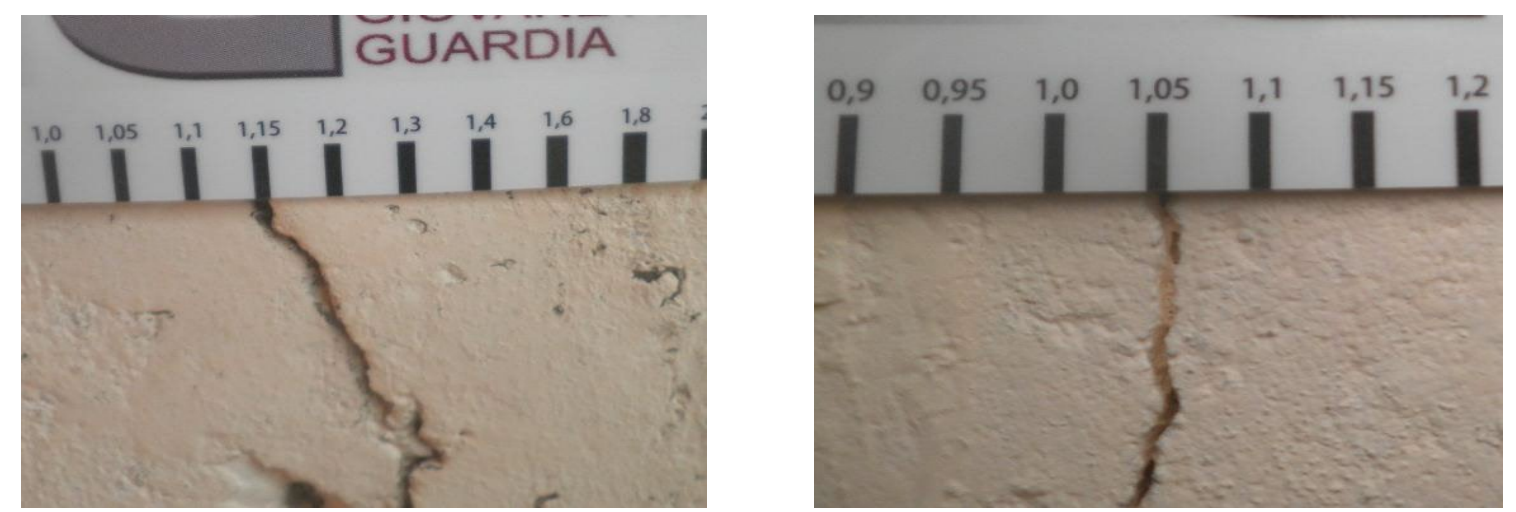

Figura 3.13. Verificação das aberturas nos pilares da quadra utilizando o fissurômetro.

Analisando as figuras 3.12 e a 3.13, verifica-se que de acordo com o fissurômetro a classificação das aberturas quanto à dimensão da mesma são respectivamente: fenda (a), fenda (b), fenda (c), rachadura (d), trinca (e), e trinca (f). Todas essas fissuras e aberturas observadas podem ter origem em diversos pontos tais como: recalque, movimentação térmica, entre outros.

Observou-se também na figura 3.14, que por baixo da camada de reboco houve o lançamento de concreto em vários pontos. Em alguns destes pontos, foi possível observar o processo corrosivo presente na armadura e a penetração de CO2. Já na figura 3.13, a causa provável para o surgimento dessas trincas presentes nos pilares pode ser devido a expansão da armadura do concreto decorrente da corrosão da mesma, resultando possivelmente no desplacamento do concreto.

Para detectar a causa provável da ocorrência dessas patologias deverá ser realizado um estudo mais detalhado. Todavia um dos fatores que talvez facilite o surgimento de patologias é o grau de porosidade do concreto, visto que este é um fator que influencia diretamente na resistência do mesmo. A intensidade dos poros do concreto é diretamente proporcional a relação a/c e inversamente proporcional a sua resistência.

\subsection{Análise dos Defeitos Construtivos}

Durante a pesquisa de campo, notou-se vários defeitos construtivos. $\mathrm{O}$ mais aparente são as deformações nos pilares, nas vigas, nas arquibancadas e no apoio da estrutura de aço da cobertura nos pilares. Essas deformações serão mostradas no decorrer desse tópico. A Figura 3.14 apresenta as imperfeições vistas nos pilares. 


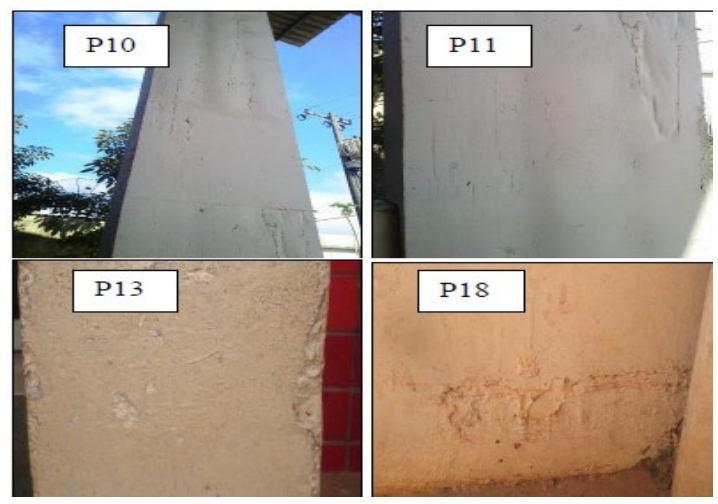

Figura 3.14. Pilares com imperfeições.

As arquibancadas da quadra do ginásio apresentam várias deformações na vista inferior das mesmas, como indica a figura 3.15. As vigas de sustentação das arquibancadas também estão com muitas imperfeições como nota-se na figura 3.15 .
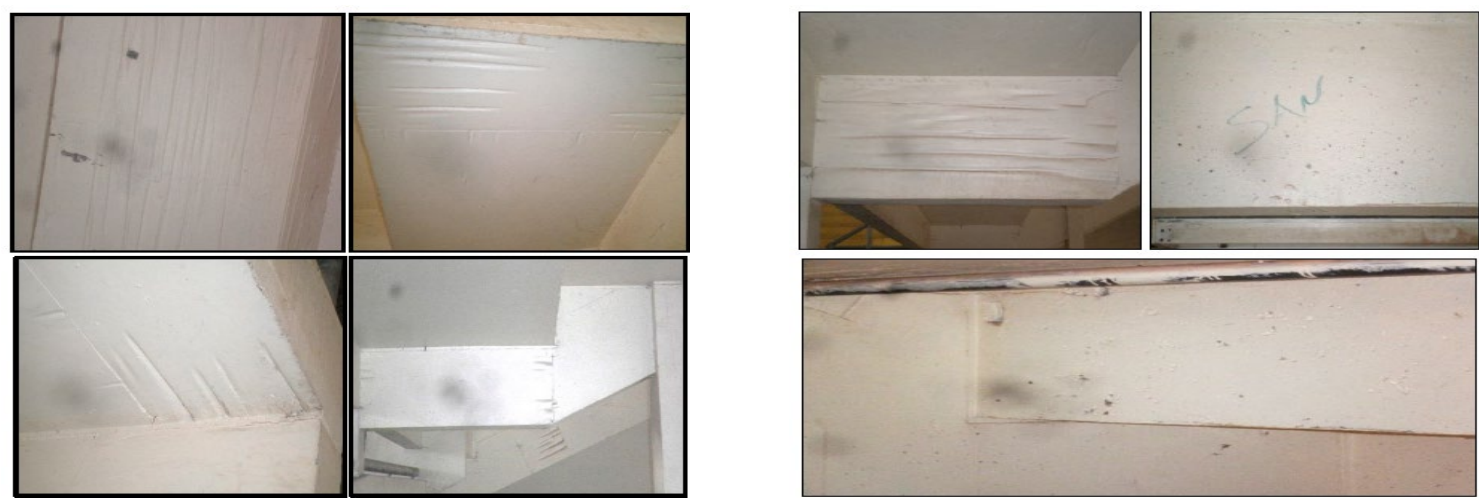

Figura 3.15. Deformação na parte inferior das arquibancadas e nas vigas.

\subsection{Corrosão nas Armaduras}

Essa patologia é uma das principais manifestações patológicas existentes no concreto armado. Sua causa pode estar relacionado há vários fatores, tais como: a espessura do cobrimento das armaduras, recomendados por normas; concreto executado com um fator a/c elevado, acarretando elevada porosidade do concreto e fissuras de retração; segregação do concreto com formação de ninhos de concretagem, entre outros.

A figura 3.16 mostra os pilares onde há a presença da armadura exposta. Na marquise e na base do guarda-corpo da quadra também foi notada a presença de armadura corroída, indicados na figura 3.17 .

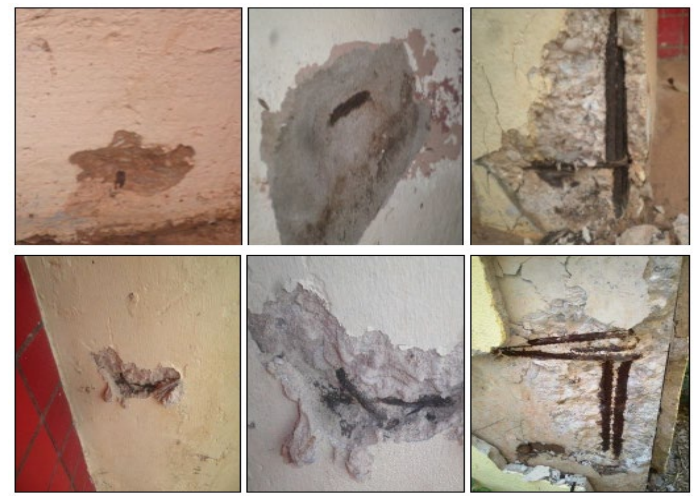

Figura 3.16. Presença de Corrosão nos pilares. 

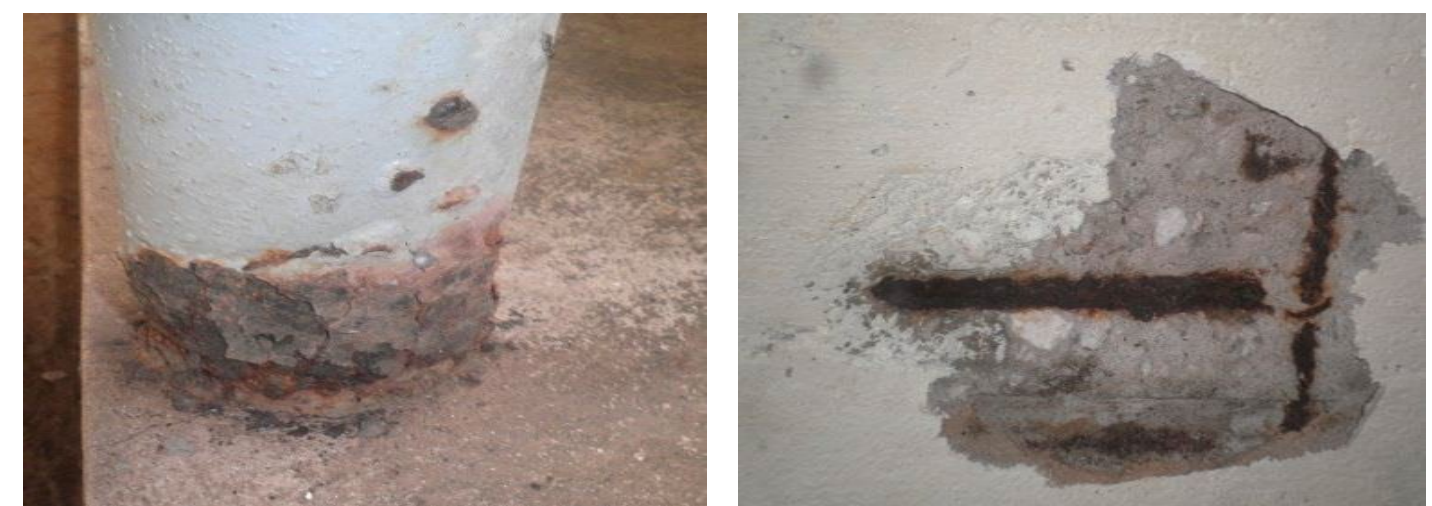

Figura 3.17. Base do guarda-corpo e superfície inferior da marquise corroída respectivamente.

Ressalta-se que com a armadura em processo de corrosão há uma diminuição na seção transversal da mesma. Para Helene (1993 apud BOTELHO e SILVA, 2008), para minimizar a corrosão da armadura, é indispensável que a armadura tenha um cobrimento adequado, sendo que isto é uma ação isolante, ou de barreira, sendo exercida pelo concreto interpondo-se entre o meio corrosivo e a armadura, principalmente quando se trata de um concreto bem dosado, com pouca permeabilidade e compacto. Essa proteção impede a formação de células eletroquímicas, através da proteção física (estanqueidade) e da proteção química (reserva alcalina). A durabilidade depende da espessura, uniformidade e estanqueidade que o concreto de cobrimento deva proporcionar ao longo do tempo às referidas armaduras e a apreciável reserva alcalina responsável pela passivação das armaduras.

Para minimizar os risco de corrosão ou mesmo elimina-los, o primeiro passo seria tomar medidas relacionadas ao projeto e execução. Há outras formas mais específicas para combater a corrosão das armaduras, como: utilização de métodos eletroquímicos, que consiste na proteção catódica e anódica da armadura; isolamento da armadura do eletrólito pelo uso de revestimentos, afirma Botelho e Silva (2008).

Necessita-se de correção, uma vez que as armaduras já estão em processo de corrosão e a partir disso, definir se a armadura será somente restaurada ou substituída. Independentemente da situação, o fato é que a armadura deve ser recuperada, para prevenir consequências futuras mais grave, como por exemplo o desabamento da estrutura.

\subsection{Análise Geral das Patologias Identificadas nas Peças de Concreto Armado do Ginásio Poliesportivo}

Durante a visita ao ginásio, identificou-se a existência de muitas patologias como já foi apresentado anteriormente. Para uma melhor visualização desses resultados, o gráfico3.2, apresenta o quantitativo de cada patologia observada.

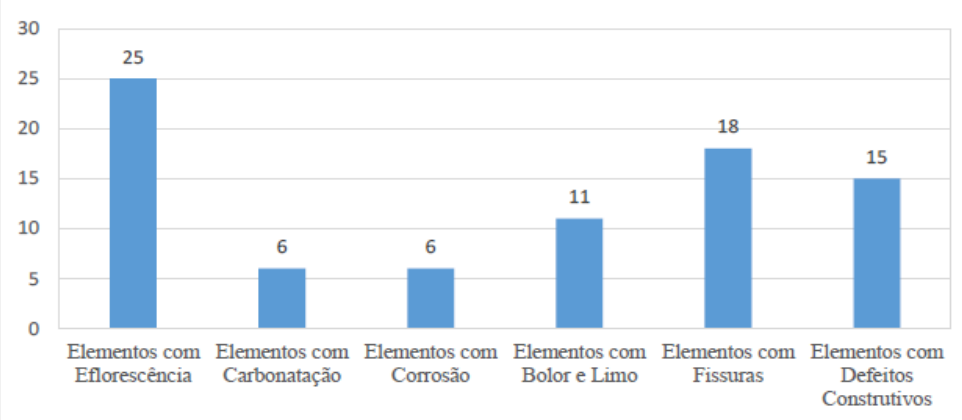

Gráfico 3.2. Quantitativo das Patologias Identificadas. Fonte - Elaboração própria. 
De acordo com o gráfico, das ocorrências analisadas na quadra poliesportiva, a maior incidência foi a de eflorescência. Almeida (2008) relata que os problemas patológicos existentes na construção civil são evidenciados geralmente por meio de manifestações externas seguindo padrões característicos. A partir do momento que essas manifestações começam a ser analisadas, possibilitam investigar os sintomas, as causas, as origens e até mesmo, estimar prováveis consequências ligadas à evolução de cada patologia encontrada, proporcionando avaliar um possível diagnóstico seguida de uma adequada solução a ser aplicada.

\subsection{Análise da Estrutura de Aço}

$\mathrm{Na}$ estrutura metálica muitos trechos de corrosão foram observados. No encontro entre a montante e o banzo inferior está corroído, com a alma da montante apresentando o aço em processo de expansão, conforme indicado na figura 3.18. As bordas das mesas e alma das peças dos banzos inferiores da treliça estão deterioradas, com perda da seção dos perfis.
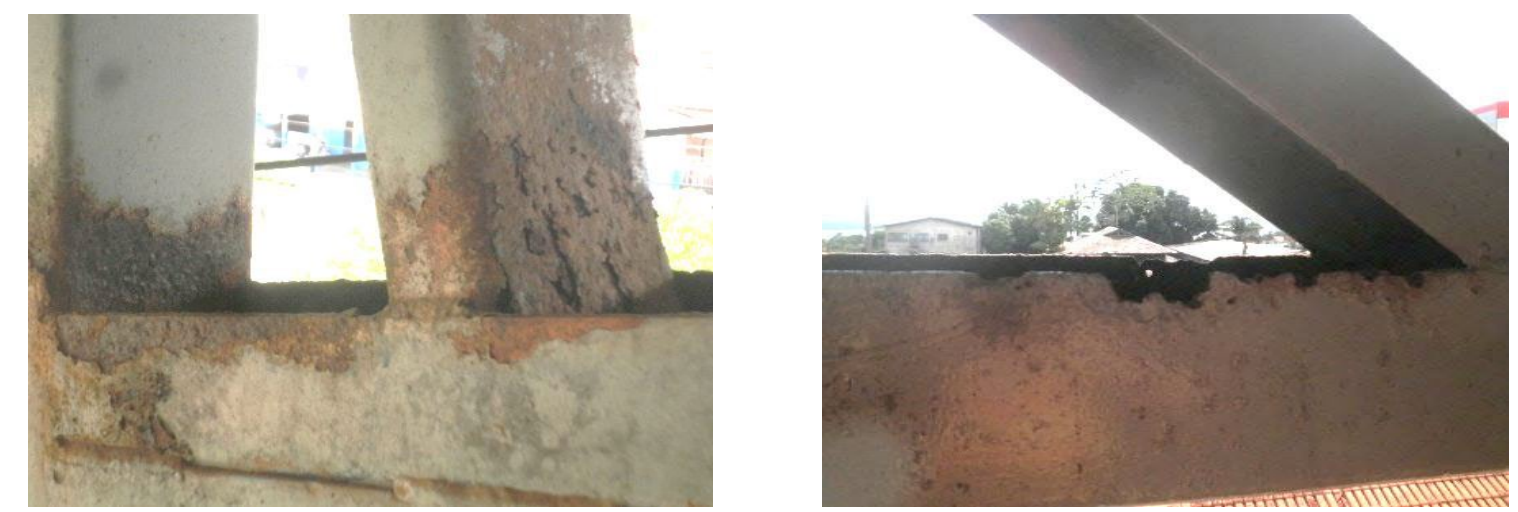

Figura 3.18. Aço em expansão na treliça e perda de perfil.

Percebe-se que em alguns pontos das treliças, os perfis da estrutura metálica do ginásio está com um elevado grau de corrosão, principalmente nas duas treliças localizadas na extremidade da estrutura. Uma das causas para tal ocorrência pode ser a exposição da estrutura a água pluviais, haja vista que dentre as nove treliças constituintes da estrutura, as mais afetadas pela corrosão são as da extremidade que estão desprotegidas das chuvas. No período do inverno, onde a frequência da chuva é maior, os banzos inferiores acumulam essa água, uma vez que não há pra onde escoar, e com isso as peças metálicas ficam em contanto direto com essa água, facilitando e intensificando o processo de corrosão. Essa deterioração da estrutura deve ser minimizada e restaurado os trechos dos perfis em que houve a perda da seção, visto que tal fator influência diretamente na resistência da peça, e por conseguinte, da estrutura como um todo.

Castro (1999) defende que o aço é um tipo material que precisa ser revestido com uma proteção, visto que a ausência dessa proteção implica na facilidade para a corrosão do aço e desproteção contra incêndio. A deterioração da armadura pode resultar na perda de estabilidade da estrutura, com isso a prevenção se torna uma ferramenta indispensável. Os meios mais usuais de prevenção contra a corrosão são a pintura e a galvanização ou ainda a adoção de aços com alta resistência à corrosão. Já a proteção contra incêndio é utilizada em determinadas circunstâncias como medida de segurança da estrutura para lhe garantir um determinado tempo de resistência ao fogo em caso do sinistro. Muitas vezes os dois revestimentos fazem parte da estética da edificação.

\section{CONCLUSÃO}

De acordo com o que foi constatado por análises visuais e ensaios efetuados in loco, pode-se concluir que durante o estudo realizado, várias patologias foram encontradas na estrutura de 
concreto armado da quadra poliesportiva. A patologia mais frequente observada principalmente nos pilares de concreto foi à eflorescência. Todavia outras patologias também foram identificadas no complexo do ginásio, tais como: carbonatação, fissuras, trincas, corrosão da armadura, bolor e limo, defeitos construtivos. No caso da corrosão da armadura dos pilares pode se tratar de uma manifestação patológica devido a presença de outras patologias como por exemplo a carbonatação que causa a despassivação da armadura, ou seja, a perda da película de proteção. As condições de exposição da estrutura de concreto armado aos agentes agressivos causadores dessas patologias, pode acarretar em danos estruturais graves, podendo levar até mesmo ao colapso dos elementos como já foi dito anteriormente. Eliminar às causas que facilitam o surgimento de anomalias estruturais, é uma forma de prevenção contra o surgimento de manifestações de outras patologias, visto que uma patologia implica no surgimento de outras agravando ainda mais o problema. As fissuras existentes nos pilares de concreto armado podem ser um sintoma da existência de alguma patologia e para realizar um diagnóstico correto é necessário fazer um levantamento de dados e informações sobre: a construção, os materiais utilizados, o tipo de fundação, a técnica de construção adotada, análise dos projetos da edificação; ou seja é um trabalho minucioso antes de diagnosticar a causa real do tipo de patologia encontrada. A presença de água é um dos principais causadores do surgimento de muitas patologias, diante disso, se faz necessário a eliminação de todos os pontos propícios a esse tipo de exposição.

\section{REFERÊNCIAS}

Almeida, L. U. S.; (2012), “ Corrosão em Armaduras de Concreto - Verificação do Processo Corrosivo em Pontes de Concreto Armado no Conjunto Feira VI, Feia de Santana - BA." Departamento de Tecnologia. Universidade Estadual de Feira de Santana. Feira de Santana, p.26.

Associação Brasileira de Normas Técnicas. (2014). NBR 6118: Projetos de Estruturas de Concreto-Procedimento. Rio de Janeiro.

Barin, D. S.(2008). “Carbonatação e Absorção Capilar em Concretos de Cimento Portland Branco com Altos Teores de Adição de Escória de Alto Forno e Ativador Químico. ” Dissertação de Mestrado. Universidade Federal de Santa Maria. Santa Maria, p.48.

Botelho, A. P.; Silva, D. da S. (20014), “Corrosão de Armadura em Estruturas de Concreto Armado." Trabalho de Conclusão de Curso. Universidade da Amazônia, Belém. P.12.

Castro, E. M. C. de. (2014), “Patologia dos Edifícios em Estrutura Metálica.” Departamento de Engenharia Civil - Programa De Pós-Graduação em Engenharia Civil. Universidade Federal De Ouro Preto, p.10.

Castro, M. D. de; Martins, R. M. (2014), “Análise e Sugestões Terapêuticas das Manifestações Patológicas de Infiltração de um Edifício com mais de 20 Anos" - Estudo de Caso. Trabalho de Conclusão de Curso - Universidade Tecnológica Federal do Paraná, Pato Branco, p.09.

Cavaco, J. R. Z. (2008), "Patologias nas Estruturas de Concreto Armado" Trabalho de Conclusão de Curso - Universidade Regional de Blumenau, p.41. 
Cunha, A. C. Q. da; Helene, P. R. L. (2021), “Depassivação das Armaduras de Concreto por Ação da Carbonatação." Boletim Técnico da Escola Politécnica da USP, Departamento de Engenharia de Construção Civil. São Paulo, p. 75.

Gomes, N. de A.; “Carbonatação do Concreto”. Centro de Ciências e Exatas e de Tecnologia Programa de Pós- Graduação em Engenharia Civil. Universidade Federal de São Carlos. Disponível em: <http://manifestacoespatologicas.blogspot.com.br/2013/05/carbonatacao-doconcreto.html>. Acesso em: 13 de jun. 2014.

Lapa, J. S. (2008), "Patologia, Recuperação e Reparo das Estruturas de Concreto." Universidade Federal de Minas Gerais, Belo Horizonte, 2008. Disponível em: < http://www.cecc.eng.ufmg.br/trabalhos/pg1/Patologia, \%20Recupera\%E7\%E3o\%20e\%20Reparo \%20das\%20Estruturas\%20de\%20Concreto.pdf>. Acesso em: 04 de mar. 2014.

Lopes, E. M.(2003), "A Influência da Umidade do Substrato no Desempenho De Revestimentos De Piso De Edifícios Dissertação”. Dissertação (Mestrado) - Escola Politécnica da Universidade de São Paulo, p.03.

Mendes, F. (2013), “Patologias de revestimentos”. Porto Alegre, 2013. Disponível em: < http://arquiteturacuriosa.blogspot.com.br/2013_12_01_archive.html >. Acesso em: 11 de ago. 2014. Ilustração.

Olivari, G (2003), “Patologia em Edificações. ” Trabalho de Conclusão de Curso - Universidade Anhembi Morumbi, São Paulo, 2003. p.67.

Peres, R. M.(2001), “Levantamento e Identificação de Manifestações Patológicas em Prédio Histórico - Um Estudo de Caso”. Dissertação (Título de Mestre em Engenharia). Escola de Engenharia, Programa de Pós-Graduação em Engenharia Civil. Universidade Federal do Rio.

Polito, G.(2006), "Corrosão em Estruturas de Concreto Armado: Causas, Mecanismos, Prevenção e Recuperação." Trabalho de Conclusão de Curso. Universidade Federal de Minas Gerais. Belo Horizonte, p.10.

Silva, A. C. S. da; Diniz, U. A. A.; Oliveira, J. B. de; Almeida, M. L. de; Souza, N. S. L de; Oliveira, S. L. de. (2010), “A Reação Alcali-Agregado e suas Características.” Departamento Acadêmico de Construção Civil - C. S. T em Construção de Edifícios. Instituto Federal de Educação, Ciência e Tecnologia do Rio Grande do Norte, Natal, p.38.

Silva, C. F. C. da; (2008), "Análise das Manifestações Patológicas de uma Edificação Residencial." Monografia (Título de Especialista em Inspeção, Manutenção e Recuperação de Estruturas). Escola Politécnica - Programa de Pós-Graduação em Engenharia. Universidade de Pernambuco, Recife, P.12.

Souza, M. F. (2008), "Patologias Ocasionadas pela Umidade nas edificações." Monografia (Especialização em Construção Civil). Escola de Engenharia, Departamento de Engenharia de Materiais de Construção. Universidade Federal de Minas Gerais. Belo Horizonte, P.57.

Vitório, A. (2003), "Fundamentos da patologia das estruturas nas perícias de engenharia." Instituto Pernambucano de Avaliações e Perícias de Engenharia. Recife, 2003. 